publication, in which twenty-three broadcasting naturalists have written in their own personal styles of those aspects of Nature in Britain with which they are most at home. Peter Scott on painting waterfowl, Maxwell Knight on reptiles, James Fisher on tits and milk bottles, and Bruce Campbell on nest-boxes, with a score of others, are all here in print, helping us to enjoy and appreciate with fresh interest the wild life around us.

This book is well illustrated in colour and blackand-white, and at its moderate price deserves a wide circulation.

R. W. HAYMAN

Malaysian Parasites, 16-34

Edited by J. R. Audy. (Studies from the Institute for Medical Research, Federation of Malaya, No. 28.) Pp. vii +471. (Kuala Lumpur : Institute for Medical Research; London: Crown Agents for Oversea Governments and Administrations, 1957.) $42 s$.

$\mathrm{T}$ HIS book comprises a set of papers on arthropod ectoparasites together with two on the known hosts of Malayan parasites generally and a useful review of the literature. The first paper is an interim review of the non-enopheline mosquitoes. (The propriety of treating these as parasites rather than predators is discussed by the editor elsewhere in the book.) Most of the book deals with mites but there is a paper on fleas and one on ticks. The papers on mites cover a certain number of non-Malayan species. The whole is an impressive tribute to the very active researches which have been pursued in this area since the War. The editor and contributors deserve every congratulation. The work is well and attractively illustrated and produced, although it is clear from the method of presentation that its stiff covers are not intended to disguise the interim nature of much of the contents. The taxonomist's road is a long one and the end is not yet. Most of the groups considered are at the beginning of the period of emergent order which follows on primeval chaos. As an example, it has been estimated that at least fifteen years will be required to raise the taxonomy of the Malayan culicine mosquitoes to the level prevailing in better-known parts of the tropics. The further stages of recognition and analysis of species complexes and, still later, the infra-specific analysis of individual species have been reached in only a very few small groups. Nevertheless, this is a heartening record of work in progress and a valuable reference book which no medical entomologist (or student of the vertebrate hosts) should be without.

P. F. Matringly

Annual Epidemiological and Vital Statistics, 1954 Bilingual edition (French and English). Pp. 617. (Geneva: World Health Organization; London: H.M. Stationery Office, 1957.) 30 Swiss francs; 50s. ; 10 dollars; 2,400 French francs.

7 NIS volume presents vital statistics for forty countries. Deaths by cause (International Abridged List, 1948) and the seasonal distribution of twenty-three major notifiable diseases are given in detail. A new section records the size and diversity of each country's medical services.

The proportion of all deaths due to senility and illdefined causes is tabulated for the first time. Of the twenty countries listed Ceylon has the highest overall proportion, just under 20 per cent. France and Belgium have consistently higher proportions than England and Wales in each age and sex group.

The public health worker will find that this book raises some interesting queries. Why, for example, is mortality from accidental deaths (p. 378) higher in female than male infants in Northern Ireland, Finland, New Zealand, Japan and Ceylon, and lower in all others, and how can the high accidental male infant mortality-rate in Scotland be reduced?

Considering the complexity of the data the tables are well set out. It is, however, sometimes difficult to find the definition of a symbol. A few misprints occur, for example, 'explication' for explanation in footnote 6 (p. 53) and a transposition of the initial figures for the total and male population of the United States aged 65-69 (p. 27).

The most efficient use of the volume will be made by using it in conjunction with earlier numbers of this series.

S. J. KILPATRICK

The Mathematical Theory of Epidemics

By Norman T. J. Bailey. Pp. viii + 194. (London : Charles Griffin and Co., Ltd., 1957.) 36s. net.

T the theoretical development of each subject a stage is reached where research is hampered by the lack of a unified and logical presentation of past work. This book meets that need for epidemiology. It presents the mathematical analysis of epidemics based on deterministic and stochastic models. The older deterministic approach to the subject, though less realistic, is shown to be a useful precursor to the more difficult probability methods. Chain binomial theory (first used by Greenwood and more recently by the author) gives encouraging results in the analysis of household outbreaks. Earlier models predict the damping of recurrent epidemics. These are now more accurately described by stochastic processes. A full bibliography is given.

The book stresses the need for suitable stochastic models of endemics and for the proper collection of data to evaluate the assumptions and results of the theory. To this end formulae are given for the estimation of the parameters used in each model. The practical difficulties of estimating such necessary constants as $\beta$, the infection-rate, are not considered.

While this book contains much of interest to public health workers such information is generally difficult to find in non-mathematical language. It is accordingly more suitable for biometricians.

S. J. Kilpatrick

\section{Family and Kinship in East London}

By Michael Young and Peter Willmott. (Reports of the Institute of Community Studies.) Pp. $x i x+232$. (London : Routledge and Kegan Paul, Ltd., 1957.) 25s. net. 7 HIS is the first of a series of reports issued by the Institute of Community Studies. It is based on interviews with 1,000 individuals living in Bethnal Green, London, a more intensive interview with fortyfive married couples in that borough, and a study of forty-seven families originally living in Bethnal Green, but re-housed on the London County Couneil housing estate in Greenleigh. The first part of the study is concerned with kinship structure, and stresses in particular the important role of the wife's mother in the domestic life of the growing household. In the second part the authors study the reactions of families re-housed in Greenleigh and discuss the implications of their findings for future housing policy. The report is extremely readable, and combines the advantages of an anthropologieal field study with more rigorous statistical analysis. It is particularly welcome as an addition to the all too rare studies of normal family life in Britain to-day.

E. Grebenik 